\title{
Very severe chronic ventricular tachycardia due to an aneurysm in the left main coronary artery and a giant aneurysm-related pseudoaneurysm
}

Changfa Guo, MD, PhD, Jiayu Zheng, MD, Hao Lai, MD, PhD, and Chunsheng Wang, MD

From the Department of Cardiac Surgery, Zhongshan Hospital, Fudan University, Shanghai, People's Republic of China.

Disclosures: Authors have nothing to disclose with regard to commercial support. C.G. and J.Z. contributed equally to the article.

Received for publication July 6, 2013; revisions received Aug 4, 2013; accepted for publication Aug 15, 2013; available ahead of print Sept 30, 2013.

Address for reprints: Hao Lai, MD, PhD, and Chunsheng Wang, MD, Department of Cardiac Surgery, Zhongshan Hospital, Fudan University, Shanghai 200032,

People's Republic of China (E-mail: Lai.hao@zs-hospital.sh.cn and Wang. chunsheng@zs-hospital.sh.cn).

J Thorac Cardiovasc Surg 2014;147:1419-20

$0022-5223 / \$ 36.00$

Copyright $\odot 2014$ by The American Association for Thoracic Surgery

http://dx.doi.org/10.1016/j.jtcvs.2013.08.027

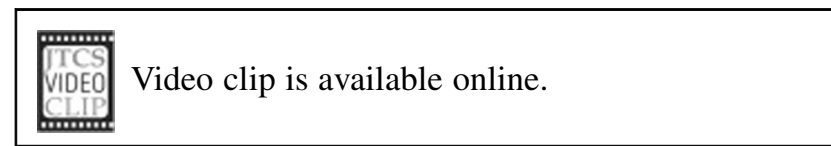

A patient presented with a very severe irregular palpitation of 10 years' duration. Holter monitoring demonstrated 22,742 polymorphic premature ventricular contractions and 934 instances of ventricular tachycardia within 24 hours. Echocardiography revealed moderate aortic valve regurgitation with a dilated ascending aorta measuring
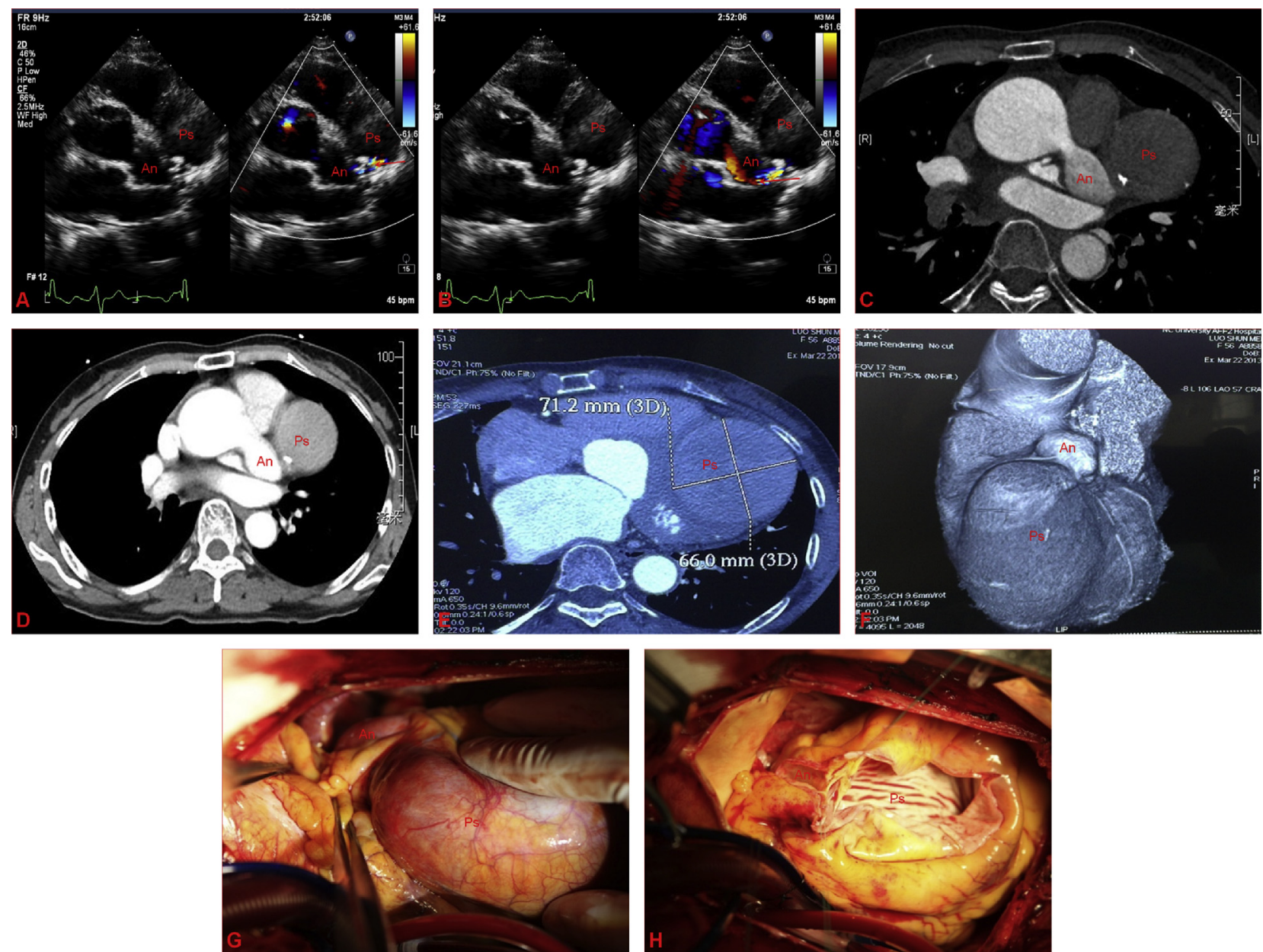

FIGURE 1. Images of the aneurysm in the left main coronary artery and giant aneurysm-related pseudoaneurysm. Echocardiography showed blood flowing (A), into and (B), out of the pseudoaneurysm (red arrow). C-F, Computed tomographic arteriography revealed the aneurysm and giant pseudoaneurysm with the largest diameter $71.2 \mathrm{~mm}$. G and $\mathrm{H}$, The images at surgery. An, Aneurysm; Ps, pseudoaneurysm; 3D, 3-dimensional. 
$5.2 \mathrm{~cm}$ in diameter. Furthermore, it revealed an aneurysm in the left main coronary artery and a giant aneurysm-related pseudoaneurysm with blood flow from the aneurysm into and out of the pseudoaneurysm (Figure 1, $A$ and $B$, Videos E1 and E2). Computed tomographic arteriography of the coronary artery confirmed the diagnosis of the aneurysm and the giant pseudoaneurysm, with the largest diameter $71.2 \mathrm{~mm}$ (Figure 1, $C-F$ ). At surgery, the aneurysm and giant pseudoaneurysm were found (Figure 1, $G$ and $H$ ), and we performed aortic valve replacement, ascending aortic replacement, reconstruction of the left main coronary artery, and pseudoaneurysm resection. The histopathologic examination confirmed the diagnosis, and the patient recovered well, with sinus rhythm postoperatively.
Some structural heart diseases (including coronary artery disease) can predispose patients to ventricular tachycardia. ${ }^{1}$ However, such a severe chronic ventricular tachycardia is rare, and an aneurysm in the left main coronary artery and a giant aneurysm-related pseudoaneurysm, as the cause, is extremely rare. Our case has demonstrated the importance of echocardiography and computed tomographic arteriography of the coronary artery in evaluating and diagnosing ventricular tachycardia.

\section{Reference}

1. O'Neill JO, Starling RC, Khaykin Y, McCarthy PM, Young JB, Hail M, et al. Residual high incidence of ventricular arrhythmias after left ventricular reconstructive surgery. J Thorac Cardiovasc Surg. 2005;130:1250-6. 